Research Article

\title{
Application of the Newmark Analysis Method in Stability Evaluation of Submarine Slope
}

\author{
Hongxian Chu $\mathbb{D},{ }^{1,2}$ Yongcai Feng $\mathbb{D},{ }^{1}$ Huijie Shi $\mathbb{D},{ }^{3}$ Liancheng Hao $\mathbb{D},{ }^{1}$ Yiqi Gao $\mathbb{D},{ }^{1}$ \\ and Yuhai Chen iD \\ ${ }^{1}$ Yantai Center of Coastal Geological Survey, China Geological Survey, Yantai 264000, China \\ ${ }^{2}$ Laboratory for Marine Minerals Resources, Qingdao National Laboratory for Marine Science and Technology, \\ Qingdao 266071, China \\ ${ }^{3}$ Qingdao Institute of Marine Geology, China Geological Survey, Qingdao 266071, China
}

Correspondence should be addressed to Huijie Shi; 57562535@qq.com

Received 26 April 2021; Revised 24 June 2021; Accepted 12 July 2021; Published 22 July 2021

Academic Editor: Yu xiang Ma

Copyright ( $) 2021$ Hongxian Chu et al. This is an open access article distributed under the Creative Commons Attribution License, which permits unrestricted use, distribution, and reproduction in any medium, provided the original work is properly cited.

The Newmark seismic time-history analysis method can take into account the effects of natural seismic peak ground acceleration (PGA), duration, and seismic frequency; seismic wave can be input into the method for simulation. This study calculates the dynamic response of the typical seabed slope of Caofeidian in the event of a similar Tangshan earthquake, and the displacement value can be used to quantitatively reflect the influence of the earthquake on the slope of the site. The allowable displacement value of the top of buildings or submarine slope can be used as a marker of security and stability analysis, which can further provide important reference for similar slope stability evaluation and offshore engineering construction.

\section{Introduction}

Slope seismic stability analysis is an important subject in the field of geotechnical engineering and seismic engineering. Because of the complexity of the problem itself and the intersection of many disciplines, the slope seismic stability analysis is still in the immature stage at present, and there is no unified and reliable standard to follow in practical application [1-3]. In recent years, the research work on slope stability and landslide mainly focuses on wave action, weather hydrate decomposition, seismic force, and rapid deposition. The influence of wave action on the stability of the slope of the seafloor mainly causes the destruction of the surface soil of the seafloor, and the partial landslide of the seafloor may even trigger a large-scale landslide. Zheng et al. proposed a kinematic method of limit analysis combined with strength reduction to accurately evaluate the real-time stability of seafloor sensitive clay slope, and the stability of seafloor sensitive clay slope is systematically studied under different wave parameters [4]. Che et al. proposed an integrated finite element model of wave-seabed interaction, and the stability of seafloor slope is closely related to the dynamic wave pressure from upper sea water [5]. Influence of gas hydrate decomposition is on the stability of seafloor slopes. Song et al. used the actual survey data, considered the dynamic intensity changes of hydrate layers in the process of hydrate decomposition, conducted numerical simulations of 3D multifield coupling of hydrate seabed slopes, and considered that the serious reduction of hydrate sediment strength is the root cause of seafloor sedimentation and slope instability [6]. Zhang et al. deduced the model to calculate the excess pore fluid pressure, and a new method is proposed to determine and calculate the safety factor of seafloor slope. The analysis shows that the decomposition of hydrates can reduce the stability of seafloor slope [7]. Shi et al. summarized the unstable mechanism of seafloor hydrate slopes and evaluated the stability of seafloor slopes in the test production area of natural gas hydrates [8]. Influence of seismic action on submarine slope and the use of the infinite slope model are more common, and the stability of submarine slope is evaluated by the extreme balance method. Zhu et al. reported that the spatial variability of porewater 
pressure and soil strength has a significant impact on the slope displacement and destruction probability of seafloor slope. The earthquake has a significant impact on the stability of submarine slope, horizontal seismic effects have a significant impact on the stability of submarine slope, and vertical seismic effects have limited impact on low slope seabed slope [9-12]. Sawyer et al. studied sediments off the coast of southern Alaska and found that sediments were less resistant to shear than expected, mainly due to the combination of high sedimentation rates and seismic vibrations. These factors combine to make offshore Alaska one of the most susceptible regions to submarine landslide hazards [13]. In order to evaluate the stability of the seafloor slope before and after the earthquake, Hsu et al. carried out the analysis of the stability of the reverse slope and indoor geotechnical test and used the method of effective stress and the method of total stress to carry out the counter analysis [14]. Roesner et al. used peak ground acceleration (PGA) for the first time to assess safety factors, and the study concluded that sandy powder on the slopes of the nice seafloor could be damaged under certain ground conditions of ground movement [15]. The coastal submarine slope is affected by ocean hydrodynamic conditions such as wave and tidal current, and the environmental conditions are complex. Therefore, the stability analysis of submarine slope needs to simulate various working conditions [16]. Shi et al. studied the stability evaluation [17] of submarine slope under the conditions of gravity, sea level change, wave action, building additional load, and earthquake force. Although the earthquake is not necessarily the most important trigger factor of submarine landslide, the instability of submarine slope caused by earthquake is the most destructive, which is a key and important factor in the evaluation of submarine stability. At present, the influence of earthquake on slope stability is analyzed by static, quasistatic, and seismic dynamic time-history analyses. There are many uncertain factors in slope stability analysis, and the traditional safety factor method cannot reflect the uncertainty of geotechnical parameters [18]. In this study, the dynamic response of the deep groove submarine slope in the front of Diantou of Caofeidian under earthquake is calculated by using the Canadian GeoStudio software and Newmark seismic dynamic time-history analysis method, and the dynamic stability of the slope is analyzed.

\section{The Principle of the Newmark Displacement Analysis Method}

The Newmark displacement analysis method is based on the concept $[1,2,19]$ proposed by Newmark in 1965, which generates permanent displacement when the actual acceleration of the slope is greater than the static yield acceleration. The Newmark method is an extension of the pseudostatic analysis method by taking into account the seismic acceleration course of slope slides. Select the acceleration time frame curve that represents the seismic motion of the site and then compare the yield acceleration to determine the permanent displacement. The method assumes the following: there is a clear sliding surface on the slope, the slope body is rigid or ideal plastic material, the loss of shear strength during the earthquake can be ignored, permanent strain occurs if the seismic stress exceeds the shear resistance, and the slope is deformed only downstream.

The method first needs to find out the yield acceleration or critical seismic coefficient $k_{y}$ of the most dangerous slip surface by the traditional limit balance bar division, which can be obtained by seismic coefficient sensitivity analysis. The difficulty of the method is to select the appropriate acceleration time frame curve to simulate the seismic motion of the slope. Selecting the acceleration-time frame curve allows double-integral calculation of permanent displacement of the most dangerous slip surfaces that exceed critical acceleration.

The calculation process for the Newmark analysis of the GeoStudio program is described. For Newmark analysis, the QUAKE/W module and SLOPE/W module of the GeoStudio program need to be coupled, first of all, to obtain the dynamic stress of the slope. Static stress can be obtained from the specific value of the initial in situ stress, and dynamic stress can be obtained by subtracting the initial static stress from the vibration stress obtained from QUAKE/W program, and the formula is as follows:

$$
\sigma_{\text {dynamic }}=\sigma_{\text {vibration }}-\sigma_{\text {static }} .
$$

The dynamic stress at the bottom of each block can be calculated by using the method of striping. The total dynamic shear force, which is the additional shear force caused by the seismic vibration, is obtained by adding the dynamic stress of each block together along the entire sliding surface.

The average acceleration value can be obtained by dividing the total shear force by the potential slip weight. This value can be obtained by each cumulative time step during the earthquake and can be shown in a graph of the corresponding safety factor (Figure 1); the average acceleration corresponding to the safety factor of 1.0 is called yield acceleration (ay). In QUAKE/W analysis, average acceleration is a comprehensive representation of actual horizontal acceleration and vertical acceleration. By definition, it is the total average acceleration that can cause the slide to break or move. The average acceleration is greater than the part of ay, indicating that the slope will move. In this example, ay is 0.048 . The area integral under the velocity-time curve gets the cumulative displacement at the time of the earthquake.

The SLOPE/W program performs the above calculations for each and all trial slides surfaces, so it is possible to find the test slides with the maximum potential displacement. For convenience, the trial slide surface can be classified by deformation rather than the safety factor to confirm that the slide has the maximum displacement.

The program described here for calculating permanent deformation is based on the inherent concepts in the Newmark slider analysis. The Newmark analysis method is applicable to certain specific situations: the procedure is ideal for situations where soil shear strength does not decrease or slightly decrease during earthquake; the analysis method is not applicable to the significant reduction in shear 


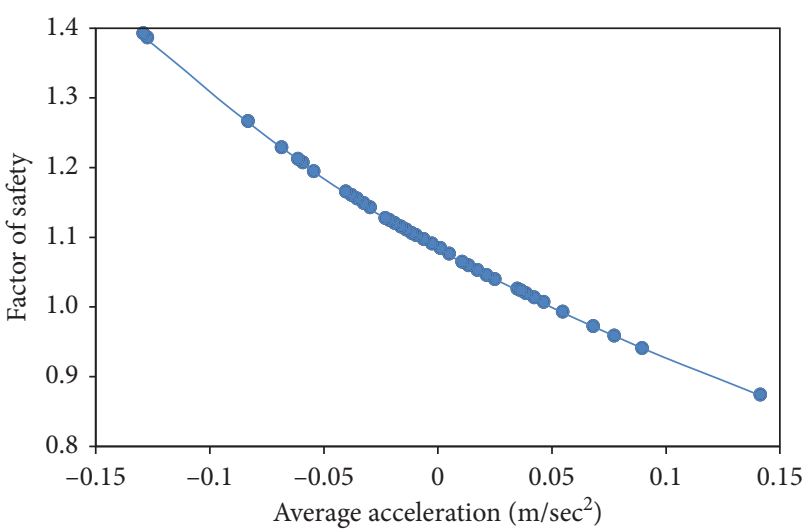

FIGURE 1: Sketch relationship of the factor of safety and the average acceleration.

strength caused by superporous water pressure or soil structure damage, such as loose sand. Kramer [20] pointed out that this method is not reliable in cases where the excess pore water pressure increases significantly during an earthquake or where the shear strength decreases by more than $15 \%$. In general, similar to the proposed static method, the Newmark method is suitable for situations dominated by inertial forces and not for situations where soil weakness becomes the key to control.

\section{Comparison of Seismic Stability Evaluation Methods for Submarine Slopes}

Quasistatic analysis method is the most widely used analysis method for slope dynamic stability analysis at present, which is characterized by clear physical meaning and simple calculation. There are mature technical standards for design reference at home and abroad. The difficulty of applying this method lies in selecting appropriate seismic coefficient and determining an acceptable safety factor value. Although the physical meaning of the seismic coefficient is the same in different specifications and technical manuals in China, it is necessary to accumulate more experience in specific application fields. The pseudostatic analysis method, which does not consider the influence of vertical earthquake, has little calculation workload, is easy to determine parameters, and accumulates rich experience in use. The pseudostatic analysis method cannot be used to evaluate the dynamic stability of slope when the soil stiffness is obviously reduced or liquefied during earthquake.

The Newmark analysis method can consider the influence of peak ground acceleration (PGA), duration, and seismic frequency of natural seismic waves and can input different seismic waves for simulation calculation. The input of different seismic waves has a significant impact on permanent displacement. The Newmark analysis method does not take the safety factor as the criterion of stability analysis but calculates and evaluates the permanent displacement of slope during earthquake as the judgment index of stability analysis. This method is common in foreign technical manuals and has accumulated considerable practical experience. Therefore, the calculation results of the Newmark analysis method are in line with the actual situation, which is relatively economical and reasonable. In this study, the Newmark analysis method is used to analyze and calculate the typical slope section of Caofeidian deep trough seabed.

\section{Newmark Analysis Application}

According to the geological investigation report of Caofeidian Ore Wharf, for the discrimination of sand liquefaction in the site, the sandy soil of 2-3 meters in the surface layer is liquefiable soil layer [21], and the liquefaction grade is medium. The other soil layers in the north side of Caofeidian are nonliquefiable soil layers, the local interlayer is fine silty sand, the sandy soil lens is liquefiable soil layer, and the silty soil lens is nonliquefiable soil layer. With Caofeidian submarine slope as the research object, the dynamic stability of slope is studied. Because the slope gradient is gentle, the global slope ratio is about $1: 0.055$, which is approximately $3.15^{\circ}$, so the slope is stable on the whole, according to Gong Hongxian. As previously studied, the damage caused by earthquakes is mainly the deep slip of the submarine slope and the displacement of the seafloor slope; the liquefied soil layer of this study is located in the shallow surface of the seafloor, and the shallow surface destruction of the surface of $2-3 \mathrm{~m}$ is not the focus and key part of dynamic analysis. The whole slope soil layer is a nonliquefaction soil layer, so the dynamic stability of the slope is evaluated comprehensively by the Newmark displacement analysis method. The slope model diagram of the seafloor is shown in Figure 2; the sea level elevation is $0 \mathrm{~m}$, regardless of the hydrodynamic influence such as wave pressure; the physical and mechanic parameters of soil in the study area have a greater dispersion; we take the average strength parameters to calculate, and the strength index of each soil layer is given in Table 1, and the strength index of the seafloor soil is used with the effect force strength parameter. In order to simulate the influence of different acceleration time-history curves and different earthquake action time on the calculation results, three acceleration time-history curves (Figure 3 ) are input in this analysis, among which the acceleration time-history curve of Tangshan earthquake wave is shown in Figure 3(c), and its peak acceleration is adjusted to $0.3 \mathrm{~g}$.

(a) The time-history curve of QUAKE/W program is shown in Figure 3(a), with seismic wave parameters: time interval $0.02 \mathrm{~s}$, duration $10 \mathrm{~s}$, and peak acceleration $0.3 \mathrm{~g}$

(b) Imperial Valley 1940 ELC-180 seismic wave is shown in Figure 3(b), with seismic wave parameters: time interval $0.01 \mathrm{~s}$, magnitude 7 , duration $39.0 \mathrm{~s}$, and peak acceleration $0.313 \mathrm{~g}$. The earthquake magnitude and peak acceleration are mainly considered when selecting this seismic wave, which are similar to the situation of this project.

(c) Tangshan earthquake wave is shown in Figure 3(c), with seismic wave parameters: time interval $0.01 \mathrm{~s}$, magnitude 7.8 , duration $39.5 \mathrm{~s}$, peak acceleration $55.49 \mathrm{~g}$, and the acceleration curve of $20-40 \mathrm{~s}$, which is intercepted 


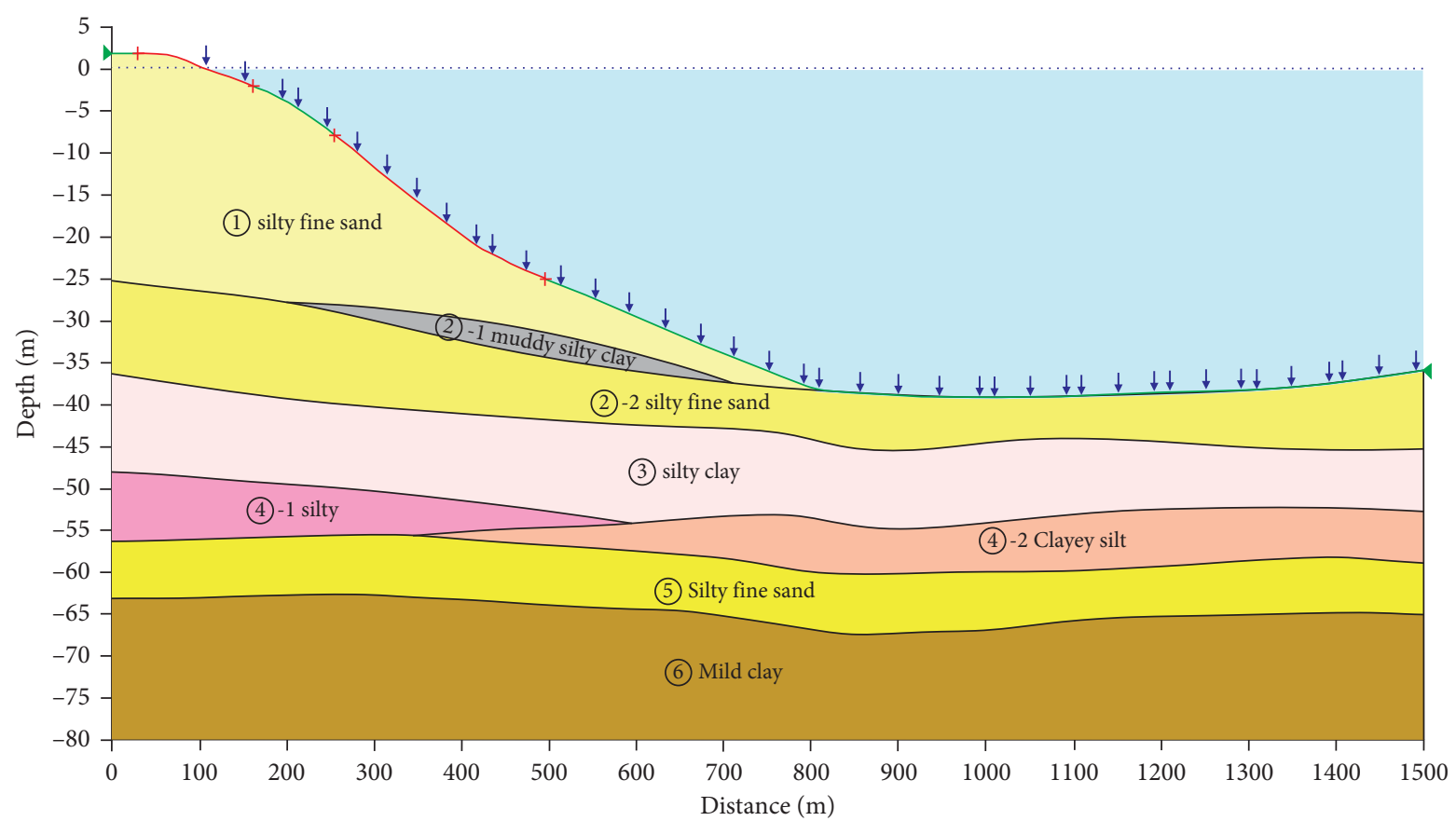

FIGURE 2: Sketch map of the underwater slope stability calculation model.

TABLE 1: The index table of physical and mechanical properties of soil.

\begin{tabular}{lccccc}
\hline Floor number & Soil name & Serious $\left(\mathrm{kN} / \mathrm{m}^{3}\right)$ & Poisson's ratio, $\lambda$ & Cohesive strength, $c^{\prime}(\mathrm{kPa})$ & Friction angle, $\phi^{\prime}\left(^{\circ}\right)$ \\
\hline (1) & Silty fine sand & 18.4 & 0.38 & 6 & 28 \\
(2)-1 & Muddy silty clay & 17.2 & 0.4 & 8 & 10.8 \\
(2)-2 & Silty fine sand & 19.1 & 0.35 & 3.3 \\
(3) & Silty clay & 19.5 & 0.35 & 23.1 & 27.2 \\
(4)-1 & Silt & 20.1 & 0.36 & 17.8 & 28.6 \\
(4)-2 & Clayey silt & 19.4 & 0.33 & 11 & 35 \\
(5) & Silty fine sand & 19.6 & 0.34 & 12 & 36 \\
(6) & Mild clay & 21.3 & 0.30 & 24.2 & 27.2 \\
\hline
\end{tabular}

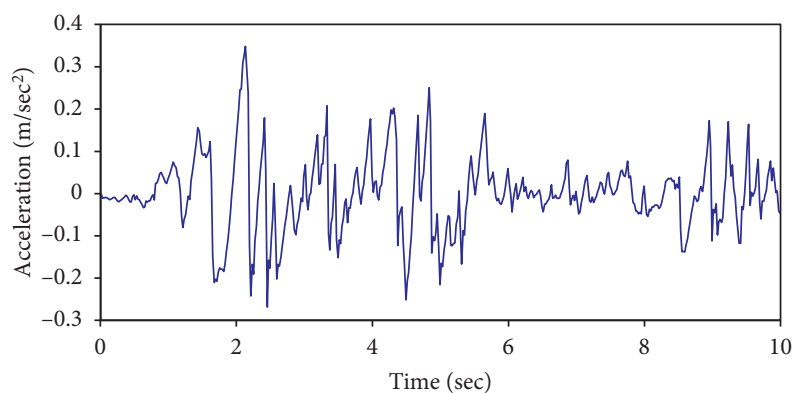

(a)

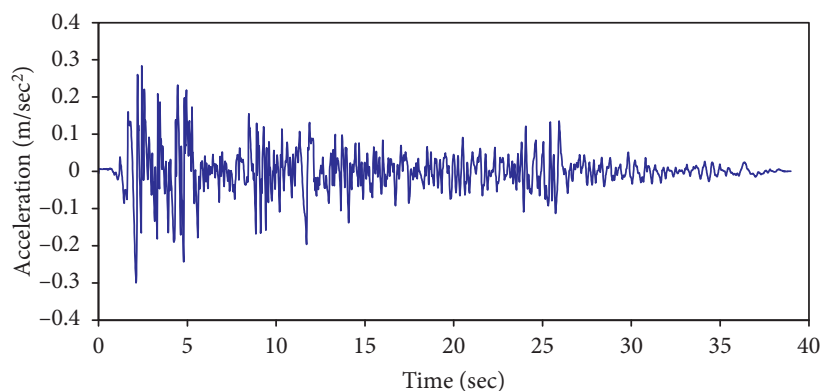

(b)

Figure 3: Continued. 


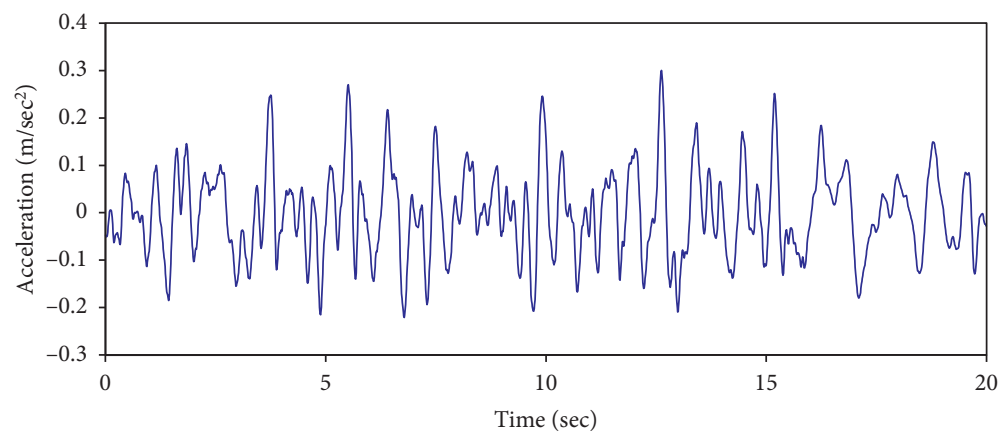

(c)

FIGURE 3: The graph of earthquake acceleration time-history. (a) QUAKE/W program. (b) Imperial Valley 1940 ELC-180 seismic wave. (c) Tangshan.

With the Newmark method, three seismic waves, namely, QUAKE/W, Tangshan earthquake wave, and Imperial Valley, are input to calculate, and the sliding slope will produce permanent displacement of $0.22 \mathrm{~m}$, $0.53 \mathrm{~m}$, and $0.11 \mathrm{~m}$, respectively, during the earthquake course. Figures 4 and 5 are the calculation results of the Tangshan earthquake wave Newmark method, and the safety factor-average acceleration relation curve, average acceleration time-history curve, velocity-time history curve, and sliding slope displacement-time curve are given, respectively.

Figure 4(a) is the safety factor changes with the average acceleration curve, reflecting the increase of the average acceleration and the decrease of the safety factor. Figure 4(b) is the sliding slope displacement-time curve, which reflects the cumulative displacement within $20 \mathrm{~s}$ of the earthquake duration. The remarkable relationship between the displacement value and waveform lies in the frequency of exceeding yield acceleration in the earthquake course. When we compare Tangshan earthquake wave and Imperial Valley earthquake wave, we can find that although they have the same maximum peak acceleration, the slope will have larger permanent displacement under the action of Tangshan earthquake wave.

At present, there are no relevant codes or technical standards at home and abroad that stipulate the allowable value of the maximum displacement. It is common practice in foreign countries to evaluate the acceptability of the maximum displacement based on the assessment indicators specified by the owners for specific projects, for example, project type and importance grade are the influencing factors of assessment.

The displacement value calculated by the Newmark method can qualitatively reflect the impact of earthquake on the site slope. In some cases, the acceptable displacement level has been used as the criterion of slope stability under earthquake action. The following cases are used as reference for safety evaluation of this project [2].

(1) The research results of Hynes-Griffin and Franklin show that the displacement of up to $100 \mathrm{~cm}$ is acceptable for the construction of dams

(2) Wieczorek et al. adopted $5 \mathrm{~cm}$ as the allowable maximum displacement of a landslide disaster in San Mateo, California

(3) Keefer and Wilson regarded $10 \mathrm{~cm}$ as the allowable displacement of a complete slope in Southern California

(4) Jibson and Keefer reported landslide in the Mississippi River Basin, and it is considered that the allowable displacement in the range of $5-10 \mathrm{~cm}$ is acceptable;

(5) California found that the displacement calculated by the Newmark method is acceptable below $15-30 \mathrm{~cm}$, the displacement larger than $30 \mathrm{~cm}$ is considered unsafe, and the displacement between 15 and $30 \mathrm{~cm}$ is considered as a "grey area," and engineering judgment is needed to evaluate its safety.

Among the three analysis methods, the permanent displacement of Imperial Valley seismic wave is $11 \mathrm{~cm}$, that of QUAKE/W seismic wave is $22 \mathrm{~cm}$, and that of Tangshan seismic wave is $53 \mathrm{~cm}$. If the intensity similar to Tangshan earthquake occurs, the slope cannot remain stable. Under the action of the other two seismic waves, combined with the results of the above pseudostatic analysis method and the sensitivity analysis of the seismic coefficient, it can be considered that some blocks of the slope will have small displacement under fortification seismic intensity, but the whole slope will not lose stability. 


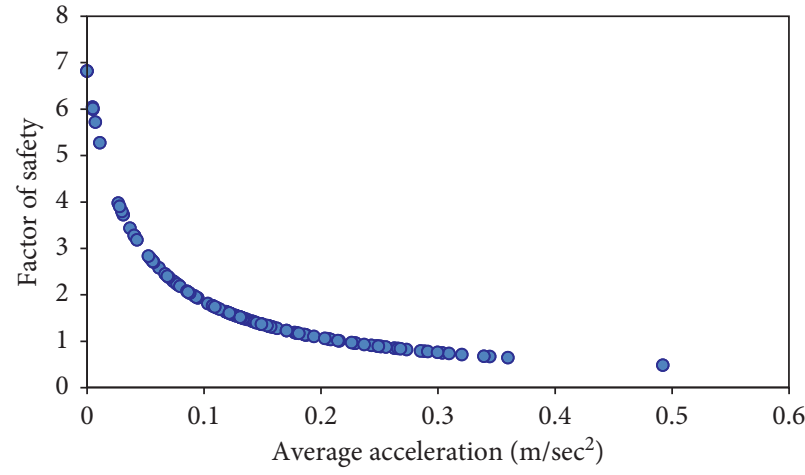

(a)

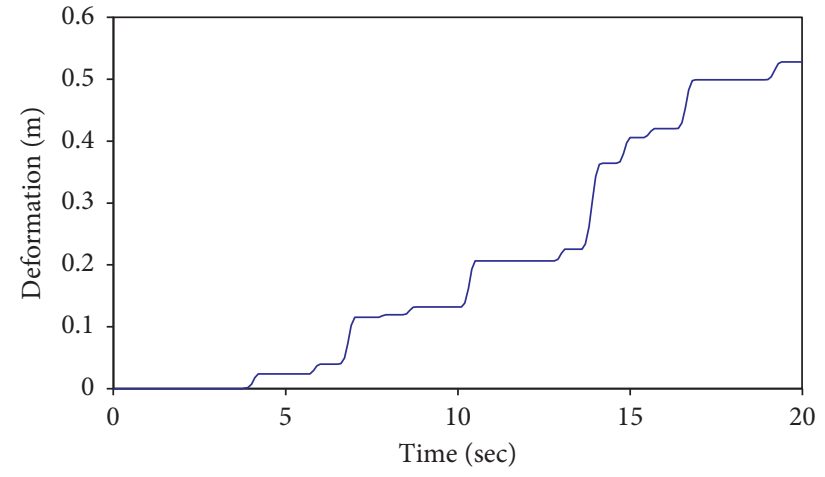

(b)

Figure 4: The graph of safety factor changing with average acceleration (a) and the graph of deformation vs. time (b) (Tangshan earthquake).

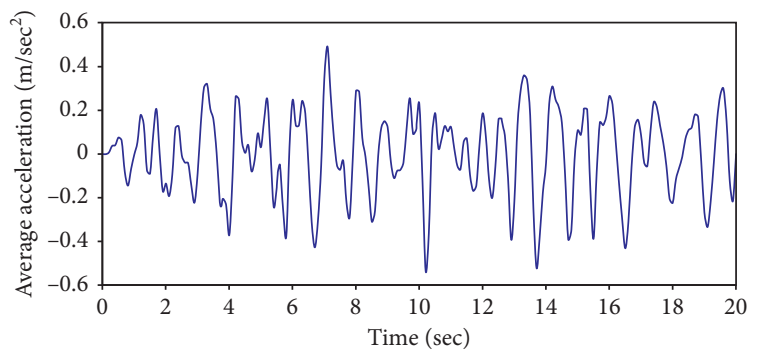

(a)

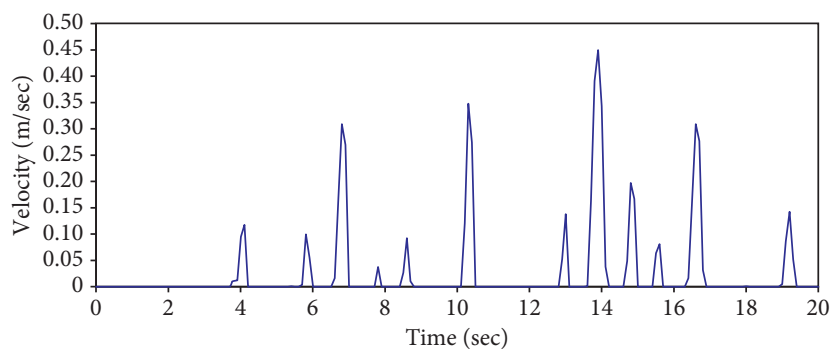

(b)

FIgURE 5: The curve of average acceleration over time (a) and the graph of velocity vs. time (b) (Tangshan earthquake).

\section{Conclusion}

In this study, the existing slope stability analysis theories are sorted out and summarized. The Newmark Method is widely used in dynamic analysis of land slopes and seldom used to study the stability of submarine slope in China. The Newmark analysis method is used to analyze and evaluate the dynamic stability of typical sections of Caofeidian deep trough; the calculated displacement value can qualitatively reflect the impact of earthquake on submarine slope, and the following conclusions are obtained:

(1) Newmark analysis method uses three acceleration time-history curves, such as QUAKE/W, Tangshan earthquake wave, and Imperial Valley earthquake wave, and analyzes and calculates the N-S section crossing the deep trough of Diantou. The calculation results show that the permanent displacement of submarine slope is $0.22 \mathrm{~m}, 0.53 \mathrm{~m}$, and $0.11 \mathrm{~m}$, respectively, under the influence of earthquake. According to the existing research results based on the Newmark analysis method, if the intensity similar to Tangshan earthquake occurs, the slope cannot maintain stability. Under the action of other two seismic waves, it can be considered that some blocks of the slope will have small displacement under the fortification seismic intensity, but the whole slope will not lose stability. Although the peak acceleration of input seismic waves is the same, the duration and seismic waveform will affect the Newmark analysis results. Under the condition of the same earthquake magnitude, the longer the earthquake lasts, the more frequently the earthquake wave exceeds the peak value and the greater the destructive effect of the earthquake force on the submarine slope is. In the cases mentioned above, the earthquake wave of Tangshan earthquake exceeds the peak value for more than 6 times, and the damage effect is relatively great.

(2) The slope soil is forced to vibrate according to the vibration form of excitation ground motion. The minimum safety factor of slope under earthquake will be greater than 1.0. Although the safety factor is greater than the critical value at a certain moment, it does not mean that the slope will be damaged at that moment. The construction of marine engineering should avoid the slope area of the seabed as far as possible, and when it is impossible to avoid it, the engineering measures of strengthening the surface soil and controlling the displacement of the seafloor should be taken to prevent the marine geological disasters caused by earthquakes. 
(3) Landslides often occur as a result of their original geological conditions and various external factors. The Newmark analysis method for landslide stability analysis has a small workload, is easy to complete, and has certain universality. It is a practical dynamic analysis method for engineering and technical researchers. The research results of this project provide an important reference for similar submarine slope stability evaluation and offshore engineering construction.

\section{Data Availability}

The data used to support the findings of this study are available from the corresponding author upon request.

\section{Conflicts of Interest}

The authors declare that they have no conflicts of interest.

\section{Acknowledgments}

The authors acknowledge their sincere thanks to those who had participated in and supported the work. This work was funded by China National Project (DD20211553) and National Natural Science Foundation of China (41506119 and 41276060).

\section{References}

[1] L. W. Abramson, T. S. Lee, S. Sharma, and G. M. Boyce, Slope Stability and Stabilization Methods, John Wiley \& Sons Inc, New York, NY, USA, 2nd edition, 2001.

[2] D. G. Anderson and G. R. Martin, "Seismic analysis and design of retaining walls, buried structures, slopes, and embankments," NCHRP Report 611, Transportation Research Board, Washington, DC, USA, 2008.

[3] Z. Y. Chen, Method, Principle and Procedure of Soil Slope Stability Analysis, Water Conservancy and Hydropower Press, Beijing, China, 2003.

[4] D. F Zheng, T. K Nian, and B. Liu, "Investigation of the stability of submarine sensitive clay slopes underwave-induced pressure," Marine Georesources \& Geotechnology, vol. 37, no. 1, pp. 116-127, 2019.

[5] W. Y. Che, C. L. Liu, Y. Li et al., "An integrated numerical model for the stability of artificial submarine slope under wave load," Coastal Engineering, vol. 158, Article ID 103698, 2020.

[6] B. Song, Y. Cheng, and C. Yan, "Seafloor subsidence response and submarine slope stability evaluation in response to hydrate dissociation," Journal of Natural Gas Science and Engineering, vol. 65, pp. 197-211, 2019.

[7] H. T. Zhang, X. Luo, J. Bi, G. He, and Z. Guo, "Submarine slope stability analysis during natural gas hydrate dissociation," Marine Georesources \& Geotechnology, vol. 37, no. 4, pp. 467-476, 2019.

[8] Y. H. Shi, Q. Y. Liang, J. P. Yang et al., "Stability analysis of submarine slopes in the area of the test production of gas hydrate in the South China Sea," China Geology, vol. 3, pp. 276-286, 2019.

[9] B. Zhu, H. Pei, and Q. Yang, "Probability analysis of submarine landslides based on the response surface method: a case study from the South China sea," Applied Ocean Research, vol. 78, pp. 167-179, 2018.

[10] Q. Yang, B. Zhu, and T. Hiraishi, "Probabilistic evaluation of the seismic stability of infinite submarine slopes integrating the enhanced Newmark method and random field," Bulletin of Engineering Geology and the Environment, vol. 80, no. 3, pp. 2025-2043, 2021.

[11] T. K. Nian, X. S. Guo, D. F. Zheng, Z. X. Xiu, and Z. b. Jiang, "Susceptibility assessment of regional submarine landslides triggered by seismic actions," Applied Ocean Research, vol. 93, Article ID 101964, 2019.

[12] S. Collico, M. Arroyo, R. Urgeles et al., "Probabilistic mapping of earthquake-induced submarine landslide susceptibility in the South-West Iberian margin," Marine Geology, vol. 429, Article ID 106296, 2020.

[13] D. E. Sawyer, R. S. Reece, S. P. S. Gulick, and B. L. Lenz, "Submarine landslide and tsunami hazards offshore southern Alaska: seismic strengthening versus rapid sedimentation," Geophysical Research Letters, vol. 44, no. 16, pp. 8435-8442, 2017.

[14] H. Hsu, J. Dong, S. Hsu, and C. Su, "Back analysis of an earthquake-triggered submarine landslide near the SW of Xiaoliuqiu," Terrestrial, Atmospheric and Oceanic Sciences, vol. 29, no. 1, pp. 77-85, 2018.

[15] A. Roesner, G. V. Wiemer, and S. Kreiter, "Impact of seismicity on Nice slope stability-Ligurian Basin, SE France: a geotechnical revisit," Landslides, vol. 16, no. 1, pp. 23-35, 2019.

[16] H. X Chu, S. Mei, S. Mei, X. H Gao, and Z. H Fang, “Analysis of formation and slope stability in caofeidian channel in bohai bay," China Geology (English Edition), vol. 2, no. 2, pp. 189-197, 2019.

[17] H. J. Shi, H. X. Chu, and X. H. Gao, "A review of submarine slope stability studies and methods," Marine Geology Frontier, vol. 29, no. 3, pp. 44-45, 2013.

[18] H. X. Chu, Z. H. Fang, H. J. Shi et al., "Bohai caofeidian submarine slope stability analysis," Ocean Engineering, vol. 34, no. 3, pp. 114-122, 2016.

[19] H. J. Shi, H. X. Chu, and X. H. Gao, "A review of submarine slope stability studies and methods," Marine Geology Frontiers, vol. 29, no. 3, pp. 44-45, 2013, in Chinese.

[20] S. L. Kramer, Geotechnical Earthquake Engineering, PrenticeHall, Upper Saddle River, NJ, USA, 1996.

[21] Z. H. Fang and H. X. Chu, "Analysis of slope stability under wave action in caofeidan deep groove," Marine Geology Frontiers, vol. 31, no. 11, pp. 29-35, 2015, in Chinese. 